\title{
Rosmarinic acid ameliorates renal ischemia reperfusion damage in rats
}

\author{
Majid Tavafi $^{\left.1^{*} \mathbb{(}\right)}$, Hassan Ahmadvand ${ }^{2}$, Ahmad Tamjidipour $^{1}$, Afshin Hasanvand $^{{ }^{\circledR}}$ \\ ${ }^{1}$ Department of Anatomy, Faculty of Medicine, Lorestan University of Medical Sciences, Khorramabad, Iran \\ ${ }^{2}$ Razi Herbal Medicines Research Center, Lorestan University of Medical Sciences, Khorramabad, Iran \\ ${ }^{4}$ Student Research Committee, Lorestan University of Medical Sciences, Khorramabad, Iran
}

\section{A R T I C L E I N F O}

\section{Article Type:}

Original

\section{Article History:}

Received: 9 June 2019

Accepted: 10 August 2019

Published online: 6 September 2019

\section{Keywords:}

Oxidative stress

Kidney

Antioxidant

Ischemia-reperfusion

Rosmarinic acid

Reactive oxygen species

\begin{abstract}
A B S T RA C T
Introduction: Reactive oxygen species (ROS) are the main factors in pathogenesis of renal ischemia-reperfusion (I/R) injury.

Objectives: The aim of this study was to evaluate the renoprotective effect of rosmarinic acid (ROA) as an antioxidant substance against renal I/R injury.

Materials and Methods: Forty male rats were divided into five groups. Group 1 control; group 2 ischemia reperfusion (I/R). Groups 3, 4 and $5 \mathrm{I} / \mathrm{R}$ treated by ROA 50, 100 and $200 \mathrm{mg} / \mathrm{kg}$ respectively. The treated groups (groups 3, 4 and 5) received ROA one hour before ischemia induction. Renal ischemia was induced by ligating of renal vessels through vascular clips. After 45 minutes of ischemia, the clips were removed to make renal recirculation (reperfusion). Twenty-four hours after the onset of reperfusion, under anesthesia blood were sampled and kidneys were removed. The serum and supernatant of renal homogenate were prepared. Serum creatinine, nitric oxide (NO) and paraoxonase (PON) were measured. The concentration of renal malondialdehyde (MDA), glutathione peroxidase (GPX), glutathione (GSH) and catalase (CAT) activity were assessed.

Results: The administration of ROA, decreased serum creatinine and increased serum NO and PON compared to group $2(P<0.05)$. Renal MDA, GSH, GPX and CAT activity improved significantly in animals that received ROA in comparison to group 2.

Conclusion: Administration of ROA improved renal I/R injuries via inhibition of lipid peroxidation and increase of GSH, GPX, CAT, NO and PON.
\end{abstract}

Implication for health policy/practice/research/medical education:

Decrease of renal ATP during ischemia and specially increase of reactive oxygen species (ROS) during renal reperfusion are the main reasons for renal injury following ischemia and reperfusion (I/R). In this study, rosmarinic acid (ROA) was administered to improve renal I/R injury. ROA attenuated renal I/R injuries through inhibition of lipid peroxidation and increase of renal glutathione (GSH), glutathione peroxidase (GPX), catalase (CAT), paraoxonase (PON) and nitric oxide (NO).

Please cite this paper as: Tavafi M, Ahmadvand H, Tamjidipour A, Hasanvand A. Rosmarinic acid ameliorates renal ischemia reperfusion damage in rats. J Nephropharmacol. 2020;9(2):e15. DOI: 10.34172/npj.2020.15.

\section{Introduction}

Renal blood vessels are ligated during the renal surgery like renal artery angioplasty, transplantation and partial nephrectomy. Following renal vessels ligation, renal hypoxia occurs and leads to kidney injury particularly proximal convoluted tubule (PCT) cells necrosis (13). After surgery and restoration of renal blood flow (reperfusion), serious damages for example tubular injuries occur during reperfusion by increasing of the reactive oxygen species (ROS) such as superoxide, hydroxyl, and hydrogen peroxide (4).

Alongside the increasing of ROS, the reduction of renal tissue antioxidant enzymes and activation of cytokines take place during the reperfusion period (5). On the other hand, PCT cells generate molecules such as TGF- $\beta$, IL-8 TNF- $\alpha$, IL- 6 and IL- $1 \beta$ during ischemic phase (6).

Numerous studies showed that I/R injury improved by using of various antioxidants. In our investigation rosmarinic acid (ROA) was used to prevent renal I/R injury. Many researchers reported that ROA shows special properties such as antioxidant (7-10), anti-inflammatory $(9,11)$, anti-Bcl-2, lowering nuclear factor kappa B, glutathione transferase increasing (12) and peroxynitrite killer (13).

Objectives

Reactive oxygen species play a pivotal role in induction of renal ischemia reperfusion injuries. ROA as a potent 
phenolic antioxidant was used to improve renal I/R damages. The effectiveness of ROA in the modulation of renal tissue antioxidant enzymes following oxidative stress associated with renal I/R have not been investigated in experimental animals. Therefore, the purpose of this research was to test the renoprotective impact of ROA as an antioxidant agent against renal I/R injury.

\section{Materials and Methods}

Forty male Sprague-Dawley rats (180-200 g) were prepared and divided into 5 equal groups randomly as follows: group 1; Control or normal, group 2; ischemiareperfusion (I/R) only, group 3, 4 and 5; I/R that received ROA 50, 100 and $200 \mathrm{mg} / \mathrm{kg}$, respectively $(10,14)$. The treated groups $(3,4$ and 5$)$ received ROA (Sigma-Aldrich USA p number 536954) orally 1 hour before ischemia induction. They were maintained at standard condition $\left(22{ }^{\circ} \mathrm{C}\right.$ and moisture of $\left.50 \% \pm 10 \%\right)$ in 12 hours, light/dark period.

\section{Method of ischemia-reperfusion induction}

After night fasting, the rats were anesthetized by chloral hydrate (400 mg/kg intraperitoneal; i.p.). Abdominal hair skin was cleaned and sterilized with povidone-iodine. Abdominal wall was incised (under xiphoid to umbilicus) and then renal ischemia was induced by renal vessels ligation through no traumatic vascular clamps. Fortyfive minutes after the onset of ischemia, the clamps were removed and kidneys were monitored for 5 minutes to confirm restoration of renal circulation and finally abdominal wall was sutured in two layers in a continuous manner $(5,15)$.

\section{Sampling}

Twenty-four hours after ischemia the blood sample was acquired from heart under anesthesia (sodium thiopental $50 \mathrm{mg} / \mathrm{kg}$ intraperitoneal; i.p.) and then the serum was prepared after blood clotting by centrifuging at $2000 \mathrm{rpm}$ for 10 minutes. The animals' right kidneys were separated and homogenized by a homogenizer in Tris-HCl buffer ( $\mathrm{pH}$ 7.4). The homogenate was centrifuged at $18000 \mathrm{~g}$ and $4 \circ \mathrm{C}$ for 30 minutes and then the supernatant was used for biochemical analysis (16).

\section{Biochemical analysis}

Renal malondialdehyde (MDA) was assessed by thiobarbituric acid test (17). The serum creatinine was assessed by special kits (Ziest Chemie Diagnostics, Tehran, Iran) according to its procedures.

Renal glutathione (GSH), glutathione peroxidase (GP) and activity of renal tissue catalase were assessed by using special kits (Pars Azmon, Tehran, Iran) according to its protocols.

The activity of serum paraoxonase (PON) was assessed by using paraoxon as a substrate according to the method explained by Ferré et al (18).
The serum nitric oxide (NO) was assessed by Griess's technique (19). Briefly, in this method sulfanilamide solution is added to serum and incubated. Then $\mathrm{N}$-naphthyl ethylenediamine dihydrochloride solution is added and again incubated. Finally, the absorption is measured by employing spectrophotometer $(530 \mathrm{~nm})$ and serum nitrate quantified by using a standard curve.

\section{Ethical issues}

This study was approved by Animal Ethics Committee of Lorestan University of Medical Sciences that was in accordance with the ethical principles of the International Committees for the Protection of Animal Rights Laboratory and National Health and Medical Research Council guidelines of the Declaration of Helsinki (proposal code; 1319).

\section{Statistical analysis}

The values were expressed as mean \pm SEM. Nonparametric Mann-Whitney U-test was used to compare the data between the groups. Statistical analysis was conducted by SPSS version 13 software. A $P$ value less than 0.05 considered significant.

Results

Influence of rosmarinic acid on serum factors in renal ischemia- reperfusion

The serum creatinine increased in group 2 in contrast to the control group and ROA administration improved it compared to group $2(P<0.05$; Table 1$)$.

The serum NO decreased in group 2 compared with the control group $(P<0.05)$. In ROA treated groups, the serum NO significantly increased in comparison with group 2 (Table 1).

Serum PON activity decreased in group 2 significantly compared to group 1 and ROA therapy in groups 4 and 5 saved it at the same level as that of group $1(P<0.05$; Table 1).

The effect of rosmarinic acid on renal MDA and renal tissue antioxidants in renal $I / R$

Renal MDA increased in group 2 compared to the control group significantly and attenuated by ROA therapy in groups 3, 4 and 5, and maintained its level similar to group $1(P<0.05$; Table 2$)$.

Renal GPX decreased in group 2 in contrast to the control group $(P<0.05)$, while treatment with ROA in groups 4 and 5 ameliorated GPX against to group 2 $(P<0.05$, Table 2).

Renal GSH diminished in group 2 compared to group $1(P<0.05)$, while after the administration of ROA, GSH maintained at the same level as that of the control group $(P<0.05)$, even ROA in group $5(200 \mathrm{mg} / \mathrm{kg})$ increased GSH in comparison with group 1 (Table 2).

Renal CAT activity improved with ROA administration in groups 4 and 5, and significantly maintained CAT 
Table 1. Results from treatment with rosmarinic acid on serum factors in renal ischemia-reperfusion

\begin{tabular}{|c|c|c|c|}
\hline Groups & Serum creatinine $(\mathrm{mg} / \mathrm{dL})$ & Serum nitric oxide ( $\mu \mathrm{mol} / \mathrm{mg}$ protein) & Serum paraoxanase $(\mathrm{mmol} / \mathrm{min} / \mathrm{mL})$ \\
\hline 1. Control & $0.61 \pm 0.04$ & $2.93 \pm 0.078$ & $26.7 \pm 4.57$ \\
\hline 2. $I / R$ & $1.19 \pm 0.2^{*}$ & $1.89 \pm 0.104^{*}$ & $10.66 \pm 1.7^{*}$ \\
\hline 3. $1 / \mathrm{R}, \mathrm{ROA}(50 \mathrm{mg} / \mathrm{kg}$ ) & $0.84 \pm 0.04 \# *$ & $2.44 \pm 0.19 *$ & $11.66 \pm 1.093^{*}$ \\
\hline 4. $\mathrm{I} / \mathrm{R}, \mathrm{ROA}(100 \mathrm{mg} / \mathrm{kg})$ & $0.75 \pm 0.03 \# *$ & $2.27 \pm 0.13 \#^{*}$ & $21.43 \pm 5.02 \#$ \\
\hline 5. $\mathrm{l} / \mathrm{R}, \mathrm{ROA}(200 \mathrm{mg} / \mathrm{kg})$ & $0.71 \pm 0.04 \# *$ & $2.39 \pm 0.34 \# *$ & $30.28 \pm 4.23 \#$ \\
\hline
\end{tabular}

Abbreviations: ROA, rosmarinic acid; I/R ischemia reperfusion.

Values represented as mean \pm SEM.

* Significant against control group at $P<0.05$. \# Significant against I/R group at $P<0.05$.

Table 2. Effect of rosmarinic acid on renal MDA and renal antioxidant enzymes in renal I/R

\begin{tabular}{|c|c|c|c|c|}
\hline Groups & $\begin{array}{c}\text { Renal MDA (nmol/mg } \\
\text { protein) }\end{array}$ & $\begin{array}{c}\text { Renal GPX } \\
\text { (U/mg protein) }\end{array}$ & $\begin{array}{c}\text { Renal GSH } \\
\text { (nmol/mg protein) }\end{array}$ & $\begin{array}{l}\text { Renal Catalase } \\
\text { (U/mg protein) }\end{array}$ \\
\hline 1. Control & $48.5 \pm 5.2$ & $212.8 \pm 37.9$ & $3.82 \pm 0.75$ & $2.17 \pm 0.47$ \\
\hline 2. $I / R$ & $98.76 \pm 15.3^{*}$ & $93.7 \pm 9.8^{*}$ & $1.42 \pm 0.09 *$ & $0.92 \pm 0.051^{*}$ \\
\hline 3. I/R , ROA (50 mg/kg) & $60.29 \pm 8.6 \#$ & $111.6 \pm 10.1^{*}$ & $5.23 \pm 0.54 \#$ & $2.60 \pm 0.106 \#$ \\
\hline 4. I/R , ROA (100 mg/kg) & $62.5 \pm 4.9 \#$ & $147.5 \pm 18.7 \#^{*}$ & $5.38 \pm 0.37 \#^{*}$ & $2.43 \pm 0.7 \#$ \\
\hline 5. I/R, ROA (200 mg/kg) & $53.29 \pm 3.74 \#$ & $134.2 \pm 13.7 \#^{*}$ & $4.92 \pm 0.42 \#$ & $2.39 \pm 0.03 \#$ \\
\hline
\end{tabular}

Abbreviations: ROA, rosmarinic acid; I/R ischemia reperfusion; MDA, malodialdehyde; GPX, glutathione peroxidase; GSH, glutathione. Values represented as mean \pm SEM.

* Significant against control group at $P<0.05$. \# Significant against I/R group at $P<0.05$.

activity at the same level as that of group $1(P<0.05$; Table 2).

\section{Discussion}

Renal vessels ligation during kidney surgeries leads to renal hypoxia (ischemia) and restoration of renal blood flow after surgery makes renal reperfusion. According to several investigations, excessive ROS production plays a fundamental role in the induction of renal I/R injuries (20). Moreover, decrease of the innate antioxidant enzymes, inflammation and endothelial dysfunction are reported in the pathogenesis of renal I/R injury. Because of the pivotal role of ROS in initiation and induction of renal I/R injury, today different compounds with ROS neutralization properties have received abundant attention.

Today there is no efficient treatment against renal I/R damages while the treatment limited to supportive care and fluid administration (21), while in some cases I/R injury may lead to renal failure. Although ROS inhibition in experimental researches showed good results against renal I/R injury, still there is no specific treatment by antioxidants for patients.

Our investigation showed that ROA ameliorates renal I/R injury through inhibition of renal MDA and increase of renal tissue antioxidants. In this study, administration of ROA ameliorated renal MDA against I/R, while treatment with ROA maintained renal MDA at the same level as normal group. Similar results were reported by the administration of different antioxidants (4,22-25).

ROS or other free radicals make lipid peroxidation and produce MDA. Hence, MDA is an index of oxidative stress. The increase of renal MDA is the result of elevation of free radicals or through the decrease of renal tissue antioxidants (26). Although reperfusion is vital for the kidney after ischemia, reperfusion increases free radicals such as ROS. Reactive oxygen species attack to double bonds in molecules such as polyunsaturated lipids especially in cell membrane, proteins and DNA (27).

In this survey increased serum creatinine ameliorated with ROA pretreatment in contrast to I/R group in line with the results reported by different antioxidants (2830 ). Based on renal I/R pathogenesis, the improvement of serum creatinine showed that ROA inhibits tubular epithelial cells injuries.

In this research GSH content, GPX and CAT activity reduced significantly in the second group, while ROA therapy ameliorated these variables compared with group 2. ROA maintained GSH and catalase at the same level as that of the control group. The similar results were reported by using different antioxidants $(4,28,30)$. GSH is one of the most important cellular compounds that protect the cells against free radicals and oxidative injury (31). Based on our research, arising of lipid peroxidation is the result of free radical production and decreasing of renal GSH, GPX and CAT activity in the animal model of renal I/R.

PON takes parts in various biochemical pathways including inhibition of lipid peroxidation, cleansing of reactive free radicals, drugs bio-activation, endoplasmic reticulum stress attenuation and control of cell proliferation/apoptosis (32). PON, an enzyme related to $\mathrm{HDL}$, is predominantly produced by the liver. Even though its biological roles have not been fully understood, 
it is reported that PON-1 hydrolyzes lipid peroxides (33) and protects liver against inflammation, liver diseases and fibrosis (34). In line with the results reported by Hekimoglu et al (35), in our study serum PON decreased by I/R. According to our study, serum PON decreased by $\mathrm{I} / \mathrm{R}$ and attenuated by ROA administration. It may be noted that the reduction of PON activity is linked to oxidative damage in the liver caused by renal I/R. The decreasing of this enzyme activity in renal I/R may be due to increased free radical production. Besides, excessive amounts of free radicals can disrupt the functions of proteins by attacking specific chemical groups in proteins.

In this study serum NO decreased in I/R group similar to Hekimoglu et al report (35) and ameliorated through ROA administration. Superoxide reacts with NO and makes peroxynitrite, the important factor of inducing renal I/R injury (36). During I/R, the reduction of NO is usually caused by endothelial dysfunction or declining activity of endothelial nitric oxide synthase (37). In this work, renal I/R reduced the serum NO level and ROA therapy increased serum NO significantly. The role of NO in pathogenesis of renal failure is still questionable. It shows harmful effects due to its direct cytotoxic and reaction with superoxide and generation of peroxynitrite. In contrast several studies reveal the useful effect of $\mathrm{NO}$ in ischemic models in regulation of vasomotor tone, immune defense modulation and neurotransmission. Hence, the dual opposite effects of NO have been suggested (38).

In summary, ROA significantly improved the serum creatinine against renal ischemia- reperfusion injury by the decrease of renal MDA, the increase of serum PON and renal GSH, GPX and catalase activity but could not maintain serum creatinine at the similar level as that of the normal group. The detailed molecular pathogenesis of the protective effect of ROA in combat with renal I/R cannot be fully described by our research, and more studies are needed in the future.

\section{Conclusion}

ROA attenuated renal I/R injuries by the inhibition of lipid peroxidation and the increase of GSH, GPX, CAT activity, PON and NO.

\section{Acknowledgements}

The authors would like to thank from Rezvan Bagheri, Bardia and Barsin Tavafi.

\section{Authors' contribution}

MT conducted the research and was responsible for writing of the manuscript. HA was responsible for biochemical analysis. AT and $\mathrm{AH}$ managed the experiments and analyzed the data.

\section{Conflicts of interest}

The authors declared no competing interests.

\section{Ethical considerations}

Ethical issues (including plagiarism, data fabrication, double publication) have been completely observed by the authors.

\section{Funding/Support}

Vice Chancellor for Research and Technology of Lorestan University of Medical Sciences supported the study.

\section{References}

1. Dorai T, Fishman A, Ding C, Batinic-Haberle I, David S. Amelioration of renal ischemia-reperfusion injury with a novel protective cocktail. J Urol. 2011;186:2448-54. doi: 10.1016/j.juro.2011.08.010.

2. Koga H, Hagiwara S, Kusaka J, Goto K, Uchino T, Shingu C, et al. New $\alpha$-lipoic acid derivative, DHL-HisZn, ameliorates renal ischemia-reperfusion injury in rats. J Surg Res. 2012; 174:352-8. doi: 10.1016/j.jss.2011.01.011.

3. Koga H, Hagiwara S, Mei H, Hiraoka N, Kusaka J, Goto $\mathrm{K}$, et al. The vitamin E derivative, ESeroS-GS, attenuates renal ischemia-reperfusion injury in rats. J Surg Res. 2012; 176:220-5. doi: 10.1016/j.jss.2011.07.039.

4. Sarac F, Kilincaslan H, Kilic E, Koldas M, Terzi EH, Aydogdu I. Methylene blue attenuates renal ischemiareperfusion injury in rats. J Pediatr Surg. 2015;50:1067-71. doi: $\quad$ 10.1016/j.jpedsurg.2014.06.018.

5. Hong X, Zhao X, Wang G, Zhang Z, Pei H, Liu Z. Luteolin treatment protects against renal ischemia-reperfusion injury in rats. Mediators Inflamm. 2017;2017:9783893. doi: 10.1155/2017/9783893.

6. Simmons EM, Himmelfarb J, Sezer MT, Chertow GM, Mehta RL, Paganini EP. PICARD Study Group: Plasma cytokine levels predict mortality in patients with acute renal failure. Kidney Int. 2004;65:1357-65. doi: 10.1111/j.15231755.2004.00512.x.

7. Huang S, Zheng Rl. Rosmarinic acid inhibits angiogenesis and its mechanism of action in vitro. Cancer Lett. 2006;239:271-80. doi: 10.1016/j.canlet.2005.08.025.

8. Bakirel T, Bakirel U, Keles OU, Ulgen SG, Yardibi H. Invivo assessment of antidiabetic and antioxidant activities of rosmary (Rosmarinus officinalis) in alloxan - diabetic rabbits. J Ethnopharmacol. 2008; 116:64-73. doi: 10.1016/j. jep.2007.10.039.

9. Lee HJ, Cho HS, Park E, Kim S, Lee SY, Kim CS, et al. Rosmarinic acid protects human dopaminergic neuronal cells against hydrogen peroxide - induced apoptosis. Toxicology. 2008;250:109-115. doi: 10.1016/j. tox.2008.06.010.

10. Tavafi $M$, Ahmadvand $H$. Effect of rosmarinic acid on inhibition of gentamicin induced nephrotoxicity in Rats. Tissue and Cell. 2011;43:392-7. doi: 10.1016/j. tice.2011.09.001.

11. Erkan, N, Ayranci G, Ayranci E. Antioxidant activities of rosmary ext ract, black seed essential oil, carnosic acid, rosmarinic acid and sesamol. Food Chem. 2008;110:76-82. doi: $10.1016 /$ j.foodchem.2008.01.058.

12. Jeanette S, Alex K, Adviye E. Oxidative stress and the use of antioxidants in diabetes. Cardiovasc. Diabetol. 2005;4:5-9. doi:10.1186/1475-2840-4-5. 
13. Tursun A, Astumi N, Hiroyuki M, Akio I, Toshitaka NA. Natural scavenger of peroxynitrites, protects against impairment of memory induced by Ab25-35. Brain Res. 2007;180:139-45. doi:10.1016/j.bbr.2007.03.001.

14. Rocha J, Eduardo-Figueira M, Barateiro A, Fernandes A, Brites D, Bronze R, et al. Anti-inflammatory effect of rosmarinic acid and an extract of Rosmarinus officinalis in rat models of local and systemic inflammation. Basic Clin Pharmacol Toxicol. 2015;116(5):398-413. doi: 10.1111/ bcpt.12335.

15. Hu L, Yang $\mathrm{C}$, Zhao $\mathrm{T}, \mathrm{Xu} \mathrm{M}$, Tang $\mathrm{Q}$, Yang $\mathrm{B}$, et al. Erythropoietin ameliorates renal ischemia and reperfusion injury via inhibiting tubulointerstitial inflammation. J Surg Res. 2012;176:260-6. doi: 10.1016/j.jss.2011.06.035.

16. Li J, Li QX, Xie XF, Ao Y, Tie CR, Song RJ. Differential roles of dihydropyridine calcium antagonist nifedipine, nitrendipine and amlodipine on gentamicin-induced renal tubular toxicity in rats. Eur J Pharmacol. 2009;620:97-104. doi: 10.1016/j.ejphar.2009.08.021.

17. Satho K. Serum lipid peroxidation in cerebrovascular disorders determined by a new colorimetric method. Clin Chem Acta. 1978;90:37-43.

18. Ferré N, Camps J, Prats E, Vilella E, Paul A, Figuera L, et al. Serum paraoxonase activity: a new additional test for the improved evaluation of chronic liver damage. Clin Chem. 2002;48:261-8.

19. Phizackerlyp J, Al-Dabbagh SA. The estimation of nitrate and nitrite in saliva and urine. Anal Biochem. 1983; 131:242-5.

20. Thiele JR, Zeller J, Kiefer J, Braig D, Kreuzaler S, Lenz Y, et al. A conformational change in C-reactive protein enhances leukocyte recruitment and reactive oxygen species generation in ischemia/reperfusion injury. Front Immunol. 2018;9:675. doi: 10.3389/fimmu.2018.00675.

21. Cavaillé-Coll M, Bala S, Velidedeoglu E, Hernandez A, Archdeacon P, Gonzalez G, et al. Summary of FDA workshop on ischemia reperfusion injury in kidney transplantation. Am J Transplant. 2013;13:1134-48. doi: 10.1111/ajt.12210.

22. Chu C1, He W, Kuang Y, Ren K, Gou X. Celastrol protects kidney against ischemia reperfusion induced injury in rats. J Surg Res. 2014;186:398-407. doi: 10.1016/j.jss.2013.07.048.

23. Wang YP, Li G, Ma LL, Zheng Y, Zhang SD, Zhang HX, et al. Penehyclidine hydrochloride ameliorates renal ischemia reperfusion injury in rats. J Surg Res. 2014;186:390-7. doi: 10.1016/j.jss.2013.07.041.

24. El Morsy EM, Ahmed MA, Ahmed AA. Attenuation of renal ischemia/reperfusion injury by açaí extract 2 preconditioning in a rat model. Life Sci. 2015;123:35-42. doi: $\quad 10.1016 /$ j.lfs.2014.11.013.

25. Lin M, Li L, Pokhrel G, Qi G, Rong R1, Zhu T. The protective effect of baicalin against renal ischemia-reperfusion injury through inhibition of inflammation and apoptosis. BMC Complement Altern Med. 2014;14:19. doi: 10.1186/1472-
6882-14-19.

26. Yurdakul T, Kulaksizoglu H, Pişkin MM, Avunduk MC, Ertemli E, Gokçe G, et al. Combination antioxidant effect of $\alpha$-tocoferol and erdosteine in ischemia-reperfusion injury in rat model. Int Urol Nephrol. 2010;42:647-55. doi: 10.1007/s11255-009-9641-y.

27. Johnson KJ, Weinberg JM. Postischemic renal injury due to oxygen radicals. Curr Opin Nephrol Hypertens. 1993; 2:625-35.

28. Cakir M, Duzova H, Baysal I, Gül CC, Kuşcu G, Kutluk $F$, et al. The effect of hypericum perforatum on kidney ischemia/reperfusion damage. Ren Fail. 2017;39:385-391. doi: 10.1080/0886022X.2017.

29. Choi EK, Jung H, Kwak KH, Yi SJ, Lim JA, Park SH, et al. Inhibition of oxidative stress in renal ischemia-reperfusion injury. Anesth Analg. 2017;124:204-13. doi: 10.1213/ ANE.0000000000001565.

30. Koç M, Kumral ZN, Özkan N, Memi G, Kaçar Ö, Bilsel S, et al. Obestatin improves ischemia/reperfusion-induced renal injury in ratsvia its antioxidant and anti-apoptotic effects: Role of the nitric oxide. Peptides. 2014;60:23-31. doi: 10.1016/j.peptides.2014.07.019.

31. Ross D. Glutathione, free radicals and chemotherapeutic agents. Mechanisms of free-radical induced toxicity and glutathione-dependent protection. Pharmacol Ther. 1988; 37:231-49.

32. Ceron JJ, Tecles F, Tvarijonaviciute A. Serum paraoxonase 1 (PON1) measurement: an Update. BMC Vet Res. 2014; 10:74. doi: 10.1186/1746-6148-10-74.

33. Aviram M, Rosenblat M. Paraoxonases 1, 2, and 3, oxidative stress, and macrophage foam cell formation during atherosclerosis development. Free Radic Biol Med. 2004; 37:1304-16. doi:10.1016/j.freeradbiomed.2004.06.030.

34. Marsillach J, Aragonès G, Mackness B, Mackness M, Rull A, Beltrán-Debón R, et al. Decreased paraoxonase-1 activity is associated with alterations of high-density lipoprotein particles in chronic liver impairment. Lipids Health Dis. 2010;9:46. doi: 10.1186/1476-511X-9-46.

35. Hekimoglu A, Toprak G, Akkoc H, Evliyaoglu O, Tas T, Kelle I, et al. Protective effect of 3-aminobenzamide, an inhibitor of poly (ADP-ribose) polymerase in distant liver injury induced by renal ischemia-reperfusion in rats. Eur Rev Med Pharmacol Sci. 2014;18:34-8.

36. Lieberthal W. Biology of ischemic and toxic renal tubular cell injury: role of nitric oxide and the inflammatory response. Curr Opin Nephrol Hypertens. 1998;7:289-95.

37. Uhlmann D, Uhlmann S, Spiegel HU. Endothelin/nitric oxide balance influences hepatic ischemia reperfusion injury. J Cardiovasc Pharmacol. 2000;36:S212-4.

38. AboZeid AA, Saka EL, Shafik NM. Effect of combination of L-Arginine and N-Acetylcysteine in rat model of renal ischemia-reperfusion injury. J American Sci. 2012;8:81421.

Copyright $\odot 2020$ The Author(s); Published by Published by Society of Diabetic Nephropathy Prevention. This is an open-access article distributed under the terms of the Creative Commons Attribution License (http://creativecommons.org/licenses/by/4.0), which permits unrestricted use, distribution, and reproduction in any medium, provided the original work is properly cited. 